\title{
SENTRA PEDAGANG KECIL SEMANAN
}

\author{
Bianca Belladina ${ }^{1)}$, Martin Halim²) \\ 1)Program Studi S1 Arsitektur, Fakultas Teknik, Universitas Tarumanagara, belladinabiancaa@gmail.com \\ 2) Program Studi S1 Arsitektur, Fakultas Teknik, Universitas Tarumanagara, martinh@ft.untar.ac.id
}

Masuk: 20-01-2021, revisi: 21-02-2021, diterima untuk diterbitkan: 26-03-2021

\begin{abstract}
Abstrak
Dwelling menurut Martin Heidegger dalam bukunya yang berjudul "Building, Dwelling, Thinking" meyebutkan bahwa dwelling sebagai sebuah konsep menghuni atau cara khas ada (dasein) di dunia yaitu untuk menetap (to stay), berkelana (to wander) dan bertahan hidup (to linger). Konsep berhuni manusia lebih ke bertahan hidup. Pada umumnya manusia tidak bisa hanya berdiam diri saja untuk bertahan hidup, manusia harus bekerja untuk memenuhi kebutuhannya dalam bertahan hidup. Lalu muncul pertanyaan "Bagaimana masyarakat kalangan bawah khususnya para pedagang berhuni?". Melihat para pedagang kecil tidak memiliki lahan berjualan sehingga banyak dari mereka berjualan di pinggiran jalan. Sentra Pedagang Kecil Semanan merupakan wadah bagi para pedagang kecil khususnya daerah Semanan, dimana para pedagang yang tidak memiliki lahan untuk berjualan sekarang mendapatkan lahan untuk berjualan sehingga para pedagang tidak perlu memakai ruas jalan lagi sebagai tempat berjualan. Selain itu proyek ini berusaha untuk menjawab kebutuhan masyarakat sekitar Semanan. Metode yang digunakan yaitu Respond to Site - Contextualism proses desain pada bangunan diwujudkan dengan adanya hubungan dengan lingkungan sekitar kebutuhan masyarakat sekitar dan masalah yang ada disekitar tapak.
\end{abstract}

\section{Kata kunci: Dwelling; Pedagang; Semanan.}

\begin{abstract}
According to Martin Heidegger, Dwelling in his book entitled "Building, Dwelling, Thinking" states that dwelling is a concept to inhabit or a unique way of being (dasein) in the world, namely to stay, wander (to wander) and survive (to linger). ). The concept of human habitation is more about survival. In general, humans cannot just stand by to survive, humans must work to meet their needs in survival. Then the question arises, "How do the lower class society, especially the traders live?" Seeing that small traders do not have land to sell so many of them sell on the side of the road. Semanan Small Traders Center is a place for small traders, especially the Semanan area, where traders who do not have land to sell now get land to sell so that traders do not need to use the road again as a place to sell. In addition, this project seeks to answer the needs of the people around Semanan. The method used is Respond to Site - Contextualism. The design process in buildings is realized by a relationship with the environment around the needs of the surrounding community and the problems that exist around the site.
\end{abstract}

Keywords: Dwelling; Semanan; Trader. 


\section{PENDAHULUAN}

\section{Latar Belakang}

Kota merupakan tempat dimana manusia melakukan banyak aktivitas bisa dibilang kota merupakan bagian dari kehidupan manusia. Permasalahan yang terjadi di perkotaan sangat mempengaruhi hampir segala aspek kehidupan manusia. Kepesatan pertumbuhan kota menunjukkan tingkat perkembangan yang sangat tinggi. Perkembangan kota dan perkembangan penduduk saling berkaitan satu sama lain, dimana banyak menimbulkan persoalan-persoalan yang terjadi yang menyangkut terhadap kota itu sendiri baik untuk masa sekarang maupun masa yang akan datang. Tidak sedikit atau banyaknya aspek - aspek yang harus di perbaiki dalam menyelesaikan permasalahan kepadatan kota untuk menciptakan keadaan kota yang lebih baik di masa depan.

Menurut Badan Pusat Statistik (2018), Jakarta Barat merupakan wilayah kota administrasi terpadat di DKI Jakarta.

Tabel 1. Penduduk, Laju Pertumbuhan Penduduk, Distribusi Persentase Penduduk Kepadatan Penduduk, Rasio Jenis Kelamin Penduduk Menurut Kabupaten/Kota, 2018-2019

\begin{tabular}{|c|c|c|c|c|c|c|c|c|c|}
\hline \multirow{3}{*}{ Kab/Kota } & \multicolumn{4}{|c|}{2018} & \multicolumn{5}{|c|}{2019} \\
\hline & \multicolumn{4}{|c|}{$\begin{array}{l}\text {-aju Pertumbuhan Penduduk, Distribusi Persentase Penduduk Kepadatan } \\
\text { ojenis Kelamin Penduduk Menurut ProvinsiKabupaten/Kota/Kecamatan }\end{array}$} & \multicolumn{5}{|c|}{$\begin{array}{l}\text { 3.1.1 Penduduk, Laju Pertumbuhan Penduduk, Distribusi Persentase Penduduk Kepadatan } \\
\text { Penduduk, Rasio Jenis Kelamin Penduduk Menurut Provinsi/Kabupaten/Kota/Kecamatan }\end{array}$} \\
\hline & \begin{tabular}{||c} 
Laju \\
$\begin{array}{c}\text { Pertumuhan } \\
\text { Penduduck per } \\
\text { Tahun per }\end{array}$
\end{tabular} & $\begin{array}{l}\text { Persentase } \\
\text { Penduduk }\end{array}$ & $\begin{array}{l}\text { Kepadatan } \\
\text { Penduduk per } \\
\text { km2 }\end{array}$ & $\begin{array}{l}\text { Rasio Jenis } \\
\text { Kelamin } \\
\text { Penduduk }\end{array}$ & $\begin{array}{l}\text { Jumlah } \\
\text { Penduduk (ribu) }\end{array}$ & $\begin{array}{l}\text { Laju } \\
\text { Pertumbuhan } \\
\text { Penduduk per } \\
\text { Tahun }\end{array}$ & $\begin{array}{l}\text { Persentase } \\
\text { Penduduk }\end{array}$ & $\begin{array}{l}\text { Kepadatan } \\
\text { Penduduk per } \\
\text { km2 }\end{array}$ & $\begin{array}{l}\text { Rasio Jenis } \\
\text { Kelamin } \\
\text { Penduduk }\end{array}$ \\
\hline Kep Seribu & 1.69 & 0.23 & 2774 & 98.86 & 24.30 & 1.79 & 0.23 & 2387 & 99.80 \\
\hline Jakarta Selatan & 1.06 & 21.46 & 15900 & 100.04 & 2264.70 & 1.18 & 21.44 & 14675 & 99.90 \\
\hline Jakarta Timur & 0.98 & 27.86 & 15508 & 101.40 & 2937.86 & 1.09 & 27.80 & 16080 & 101.20 \\
\hline Jakarta Pusat & 0.29 & 8.83 & 19212 & 99.37 & 928.11 & 0.34 & 875 & 17719 & 99.20 \\
\hline Jakarta Barat & 1.43 & 24.45 & 19757 & 101.73 & 2589.93 & 1.60 & 24.61 & 20813 & 101.60 \\
\hline Jakarta Utara & 1.10 & 17.17| & 12255 & 98.04 & 1812.91 & 1.22 & 17.17 & 12950 & 97.90 \\
\hline DKI Jakarta & 1.07 & 100 & 15804 & 100.42 & 10557.81 & 1.19 & 100 & 15900 & 100.24 \\
\hline
\end{tabular}

Sumber: Badan Pusat Statistik, 2018

Penulis mengambil kelurahan Semanan. Semanan merupakan salah satu kelurahan dari kecamatan Kalideres. Kawasan ini didominasi oleh permukiman dan pabrik. Sebagian penduduk kalangan bawah dikelurahan Semanan pekerjaan utamanya yaitu berdagang. Para pedagang memakai bahu jalan disepanjang jalan semanan raya. karena terbatasnya lahan di lingkungan ini membuat masyarakat tidak mempunyai wadah atau tempat untuk menampung para pedagang sehingga para pedagang memakai bahu jalan.

Berdasarkan teori Martin Heidegger (1971) dalam bukunya yang berjudul "Building, Dwelling, Thinking" menyebutkan bahwa dwelling sebagai sebuah konsep menghuni atau cara khas ada di dunia, yaitu untuk menetap, berkelana, dan bertahan hidup. Penulis fokus kepada pernyataan bertahan hidup "Bagaimana masyarakat kalangan bawah khususnya para pedagang berhuni?" Karena berdagang merupakan cara mereka untuk bertahan hidup.

\section{Rumusan Permasalahan}

a. Para pedagang disepanjang Jl. Semanan Raya menggunakan bahu jalan untuk berdagang sehingga membuat masyarakat menggunakan jalan sebagai tempat parkir saat membeli.

b. Pada kelurahan Semanan sebagian besar masyarakat didominasi oleh kelompok umur 0-19 tahun, anak-anak tidak memiliki tempat bermain yang memadai, sedangkan bermain dan belajar merupakan aktivitas banyak anak-anak di kelurahan ini.

c. Pada kelurahan Semanan tidak memiliki area terbuka hijau. Dan kurangnya minat masyarakat dalam bercocok tanam. Sedangkan unsur alam sangat penting bagi kehidupan manusia. 
d. Pada kelurahan Semanan sebagian besar masyarakat didominasi oleh kelompok umur 0-19 tahun, anak-anak tidak memiliki tempat bermain yang memadai, sedangkan bermain dan belajar merupakan aktivitas banyak anak-anak di kelurahan ini.

e. Pada kelurahan Semanan tidak memiliki area terbuka hijau. Dan kurangnya minat masyarakat dalam bercocok tanam. Sedangkan unsur alam sangat penting bagi kehidupan manusia.

\section{Tujuan}

Tujuan Umum

a. Menciptakan wadah atau tempat kegiatan berdagang (Jual-beli) untuk Pedagang Kaki Lima dan warga sekitar.

b. Menghadirkan tempat bermain bagi masyarakat khusus nya bagi anak-anak.

c. Menciptakan wadah interaksi untuk berkumpul dan beraktivitas untuk masyarakat Semanan

Tujuan Khusus

a. Meningkatkan kualitas hidup dan cara berhuni (dwelling) bagi rakyat kalangan bawah

b. Meningkatkan kualitas Ekonomi, Sosial, Budaya dan Pendidikan di kelurahan Semanan

\section{KAJIAN LITERATUR}

Christian Norberg-Schulz (1985) pada buku "The Concept of Dwelling" menyatakan bahwa Dwelling/hunian mempunyai makna lebih mendalam dari sekedar atap yang menaungi diatas kepala kita. Dwelling yang artinya "huni/berhuni" tidak hanya fokus pada tempat tinggal atau hunian tetapi kontribusi menyeluruh dalam kehidupan manusia di bumi

Martin Heidegger (1971) menggunakan istilah dwelling sebagai sebuah konsep menghuni atau cara khas ada (dasein) di dunia.
a. Menetap (to stay)
b. Berkelana atau Mengembara (to wander)
c. Bertahan Hidup (to linger)

Geoffrey Broadbent (1973) dalam bukunya "The Design in Archirecture" menjelaskan setidaknya terdapat 4 pedekatan dalam perancangan arsitektur yang di kenal sebagai cara ayau metode perancangan dalam arsitektur. Salah satu dari keempat pedekatan dalam perancangan arsitektur yaitu pendekatan desain secara pragmatis (Pragmatic Design).

Desain pragmatis, penciptaan bentuk tiga dimensional atau proses desain secara pragmatis, mengacu pada proses coba-coba atau mencoba-coba (trial and error), dengan memanfaatkan sumber daya (material) yang ada sedemikian rupa memenuhi maksud yang ingin di capai.

David Sim (2019) pada bukunya yang berjudul "Soft City" menunjukan bagaimana kota-kota dengan kepadatan tinggi yang di rancang dengan baik dapat menghasilkan kualitas hidup yang lebih tinggi. Sim menunjukkan bagaimana membuat kota lebih efisien, lebih layak huni, dan lebih terhubung dengan lingkungan. Kota harus mempertimbangkan organisasi dan tata letak lingkungan yang dibangun untuk pergerakan dan kenyamanan yang lebih lancar, beragam jenis bangunan dan desain yang bijaksana untuk memastikan lingkungan dan masyarakat perkotaan yang berkelanjutan. 


\section{METODE}

Pada penelitian ini metode yang dipakai adalah metode Respond to Site - Contextualism by Kari Jormakka (2003), proses desain pada bangunan diwujudkan dengan adanya hubungan dengan lingkungan sekitar, kontekstual yang dimaksud lebih mengarah desain yang disesuaikan oleh konterks site, lingkungan sekitar, kebutuhan masyarakat sekitar dan masalah yang ada disekitar tapak. Proyek merupakan wadah bagi para pedagang kecil di sekitar semanan yang tidak memiliki lahan untuk berjualan, dimana para pedagang tersebut menggunakan ruas jalan sebagai lahan untuk mereka berjualan. Selain itu program pendukung dalam proyek didapat juga dari hasil analisis-sintesis yang meliputi pengumpulan data (input), analisis (proses), dan sintesis (output). Selain itu pengamatan grounded secara langsung (survei lapangan) untuk melihat kebutuhan penduduk sekitar Semanan. Program pendukung tersebut diantaranya yaitu Children Space, Open/Public Space dan Harvesting. Program ruang yang ada didalam proyek merupakan dari hasil analisis kebutuhan dan permasalahan yang ada di sekitar tapak.

\section{DISKUSI DAN HASIL}

Proyek ini dinamakan Sentra Pedagang Kecil Semanan, proyek ini diharapkan dapat menjadi sebuah wadah bagi para pedagang sekitar Semanan yang sebelumnya tidak memiliki tempat untuk berdagang. Selain itu proyek juga diharapkan dapat memberikan kebutuhan masyarakat sekitar Semanan seperti children space dan open/public space sebagai program penunjang di dalam proyek.

Proyek berada di Jl. Semanan Raya, Kelurahan Semanan, Kecamatan Kalideres, Jakarta Barat. Lokasi proyek ini dikelilingi oleh permukiman penduduk setinggi 1-2 lantai dan area pabrik atau industri.

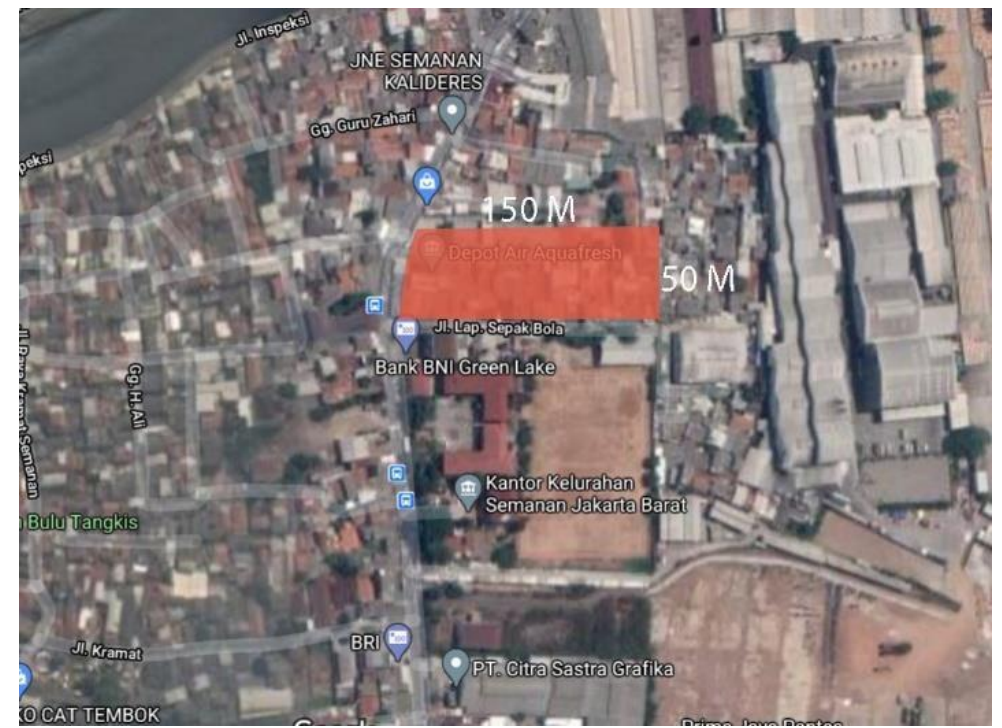

Gambar 2. Bentuk Tapak Terpilih

Sumber : Dokumentasi Pribadi

Luas Lahan : $7.500 \mathrm{M}^{2}$

Zonasi : I.1 (Industri)

$\left.6.000 \mathrm{M}^{2}\right) \mathrm{KDB}$

$\left.\mathrm{M}^{2}\right) \quad \mathrm{KTB}$

$\left.\mathrm{M}^{2}\right)$

$\mathrm{KDH} \quad: 30 \%\left(\right.$ Maksimal $2.250 \mathrm{M}^{2}$ )
KLB : 0.8 (Maksimal

: 40\% (Maksimal 3.000

: 55\% (Maksimal 4.125

KB 2 
Ini merupakan data tapak sebagai batasan atau acuan dalam membangun proyek Sentra Pedagang Kecil Semanan. Dari data tersebut penulis dapat memaksimalkan kebutuhan dan penggunaan lahan yang ada.

Zonasi pada tapak disesuaikan dengan lingkungan sekitar dan kebutuhan dari setiap program yang ada pada bangunan. Program open/public space diletakkan pada bagian depan (Jl. Semanan Raya) tapak agar dapat terintegrasi dengan area permukiman yang berada di sebrang tapak. Untuk program culinary (PKL) dan retail (Kios) berada di bagian tengah tapak agar mudah terintegrasi dari area masuk bagian depan, belakang dan samping. Untuk program Children space berada di sisi samping agar dekat dengan SDN Semanan 07 PT dan SDN Semanan 01 PG untuk memudahkan integrasi bagi murid sekolah. Terakhir untuk program harvesting diletakkan di bagian belakang tapak (bagian timur) untuk pemanfaatan cahaya matahari secara optimal.

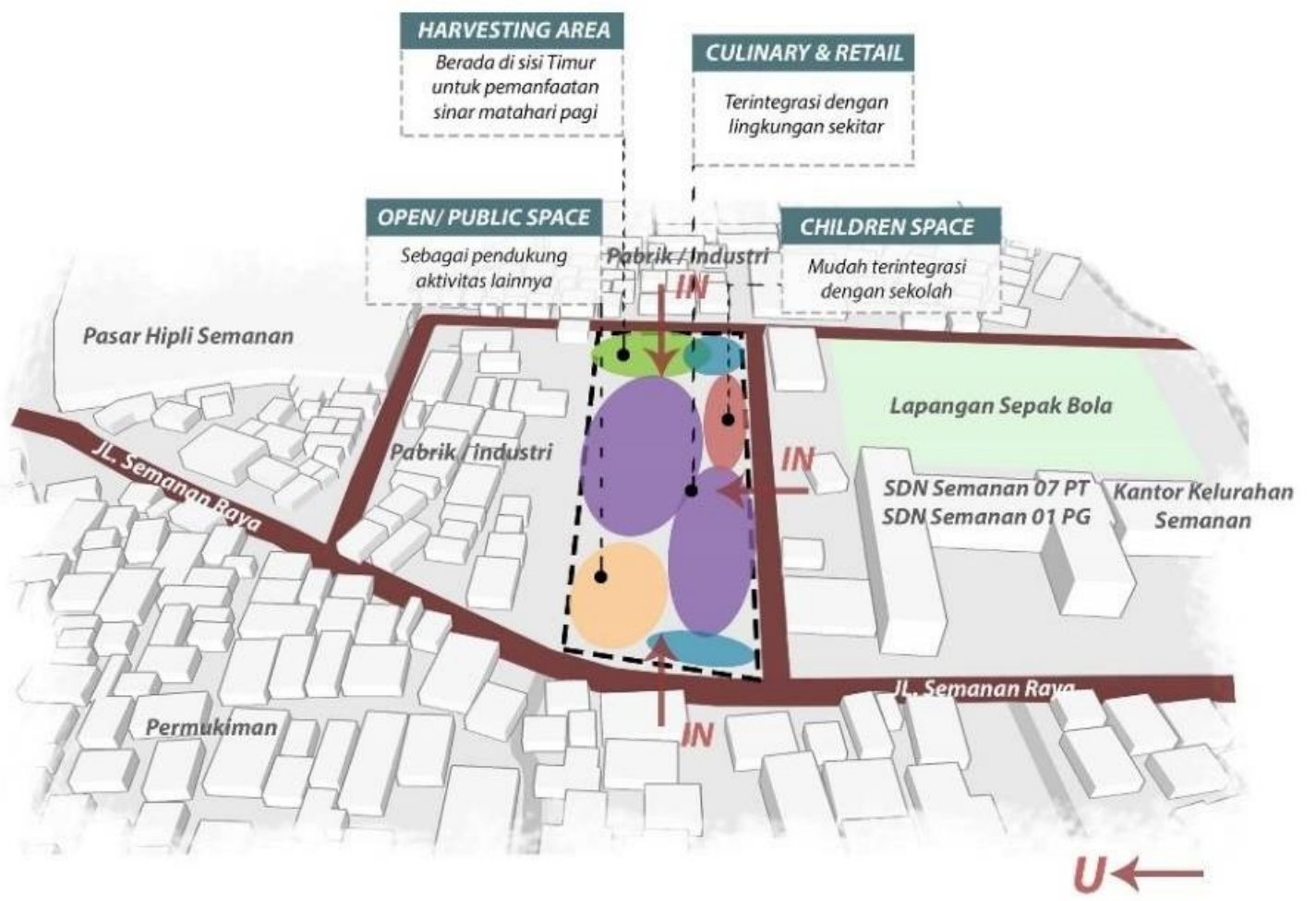

Gambar 3. Zonasi pada Tapak

Sumber: Penulis, 2020 


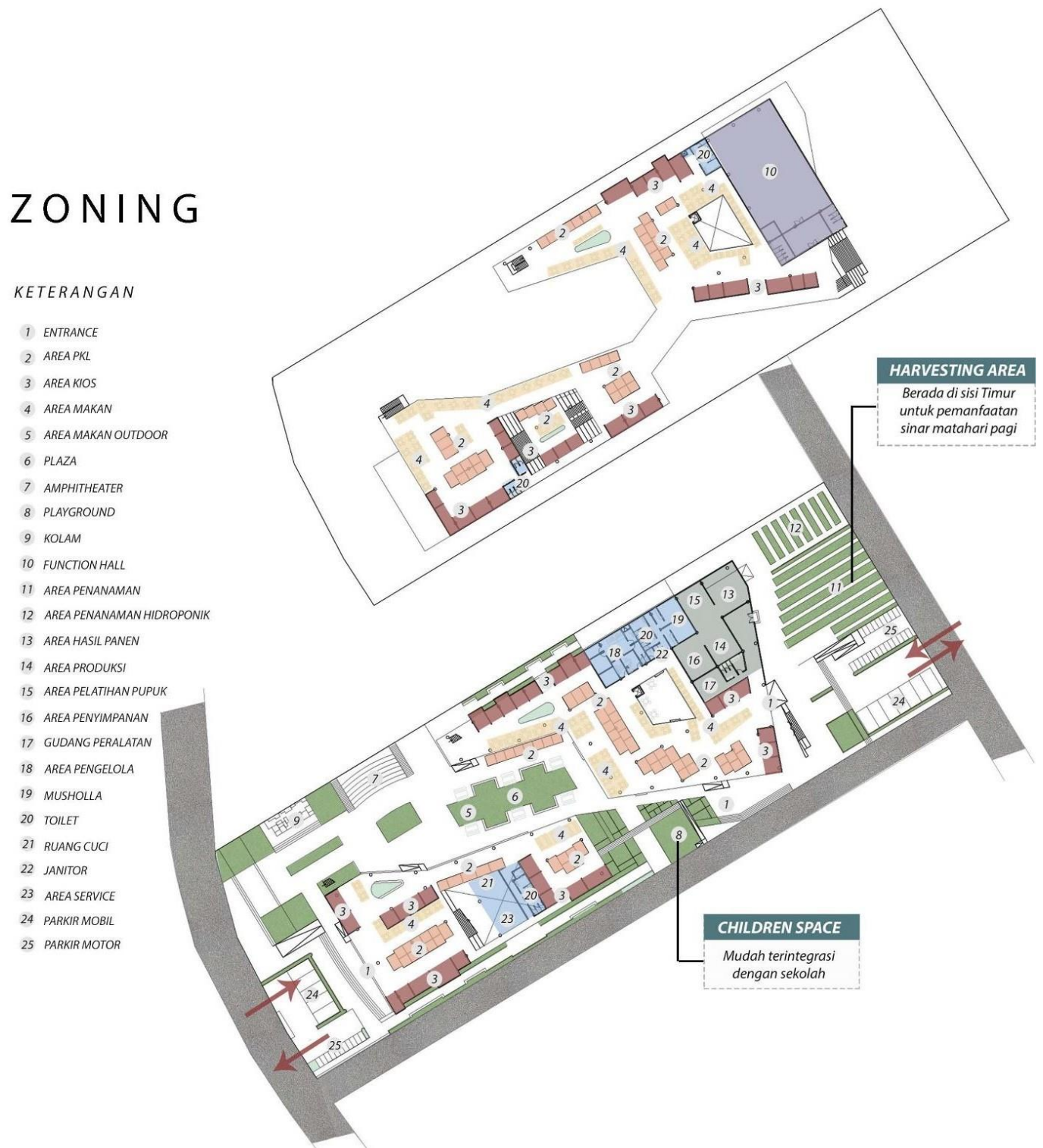

Gambar 4. Zoning bangunan

Sumber : Penulis, 2020

Pada lantai 1 terdapat children space dan harvesting area. Children space di letakan di samping agar mudah terintegrasi dengan sekolah SDN Semanan yang berada di sebelah kanan tapak.

Harvesting diletakkan di bagian kiri belakang untuk mendapatkan pemanfaatan sinar matahari pagi. Culinary dan kios diletakkan tersebar pada lantai 1 dan lantai 2 agar memberikan kesan karakter pedagang kaki lima yang mudah dicapai. Pada lantai 1 terdapat plaza yang membagi bangunan menjadi 2, alasan bangunan pada lantai 1 dibagi menjadi 2,karena bangunan diapit oleh area permukiman di sisi barat dan di sisi timur merupakan area pabrik, sehingga pencapaian dari masing- masing sisi untuk ke dalam bangunan tidak terlalu jauh. Area open/public space diletakkan di sisi barat agar mudah terintegrasi dengan area permukiman .

Proses gubah massa didapat dari hasil analisis dan hasil zoning selain itu bentuk massa juga menyesuaikan dengan lingkunagn sekitar yang didominasi oleh pabrik dan permukiman sederhana. Hal ini juga untuk menghindari bentuk dasar bangunan yang terlalu menonjol dibandingkan bangunan-bangunan lain yang ada di lingkungan sekitar. 

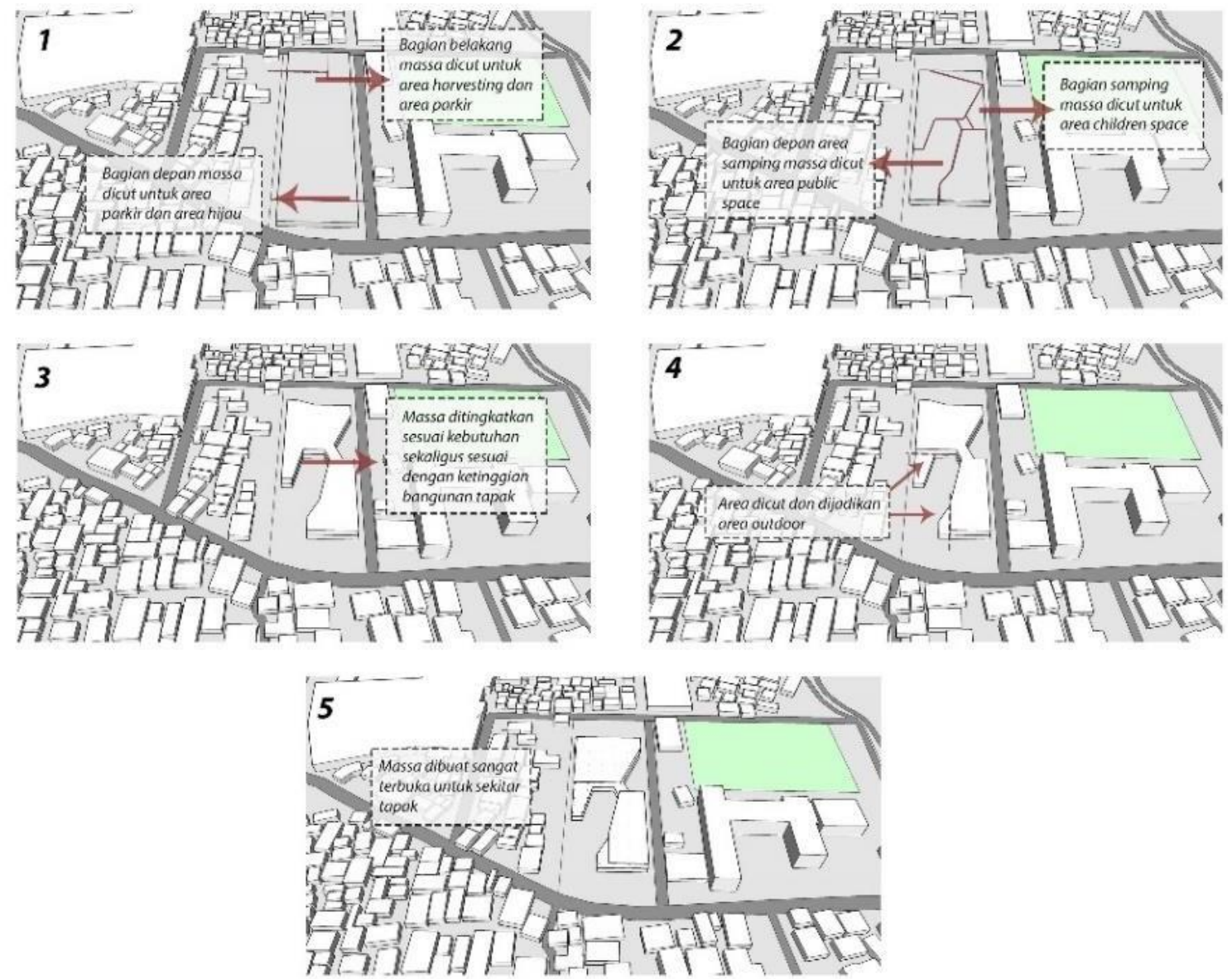

Gambar 5. Proses Gubah Massa

Sumber : Penulis, 2020.

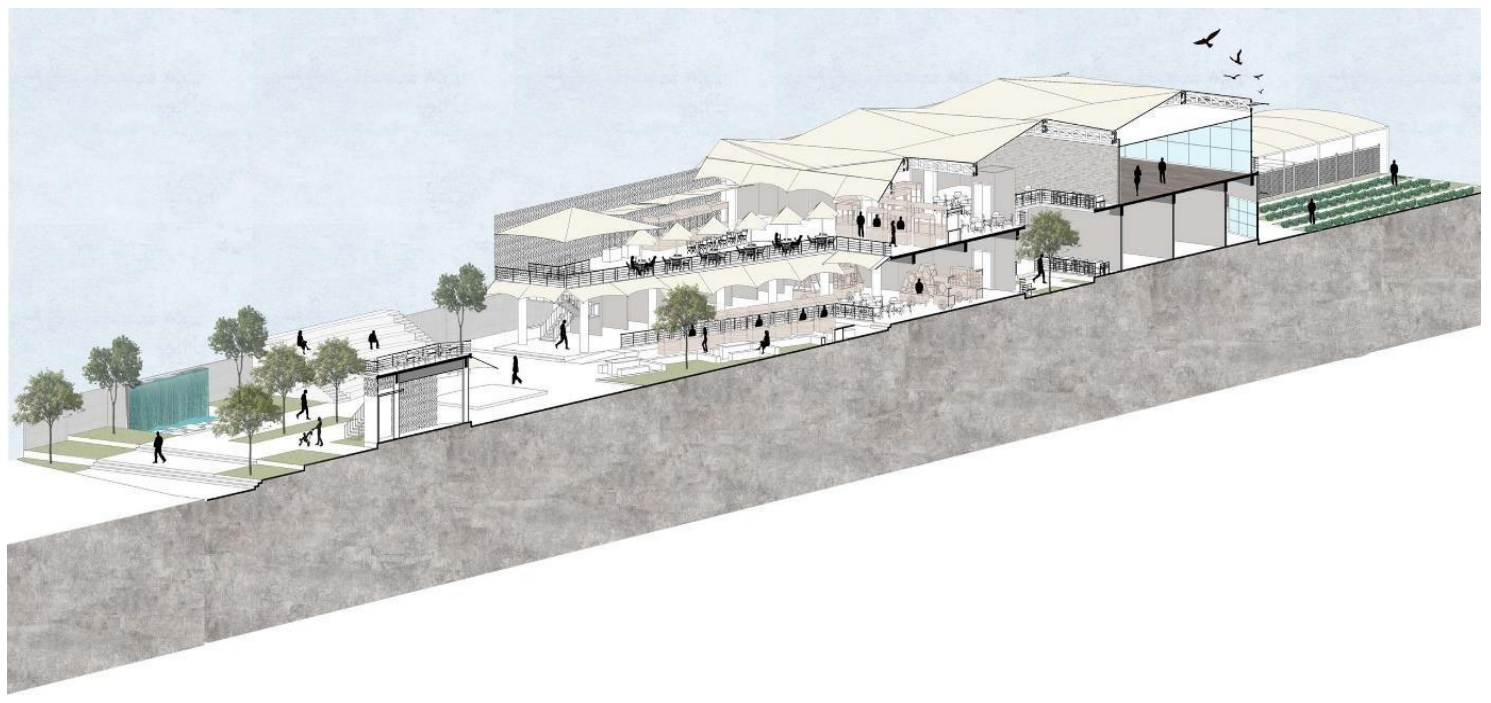

Gambar 6. Potongan Perspektif

Sumber: Penulis, 2020 
Terlihat di potongan perspektif bangunan dibuat dengan memberikan kesan transparan atau terbuka, karena karakter pedagang kaki lima yang mudah terlihat dan mudah dicapai sehingga bangunan ini dibuat tidak tertutup melainkan terbuka. Selain itu dengan sifat bangunan yang terbuka ini juga memaksimalkan pencahayaan dan pengudaraan alami pada bangunan. Penggunaan atap pada bangunan ini juga menyesuaikan dengan sifat pedagang kaki lima yang menggunakan tenda sehingga bangunan ini menggunakan atap berbahan membrane. Struktur pada atap membrane ini menggunakan baja.

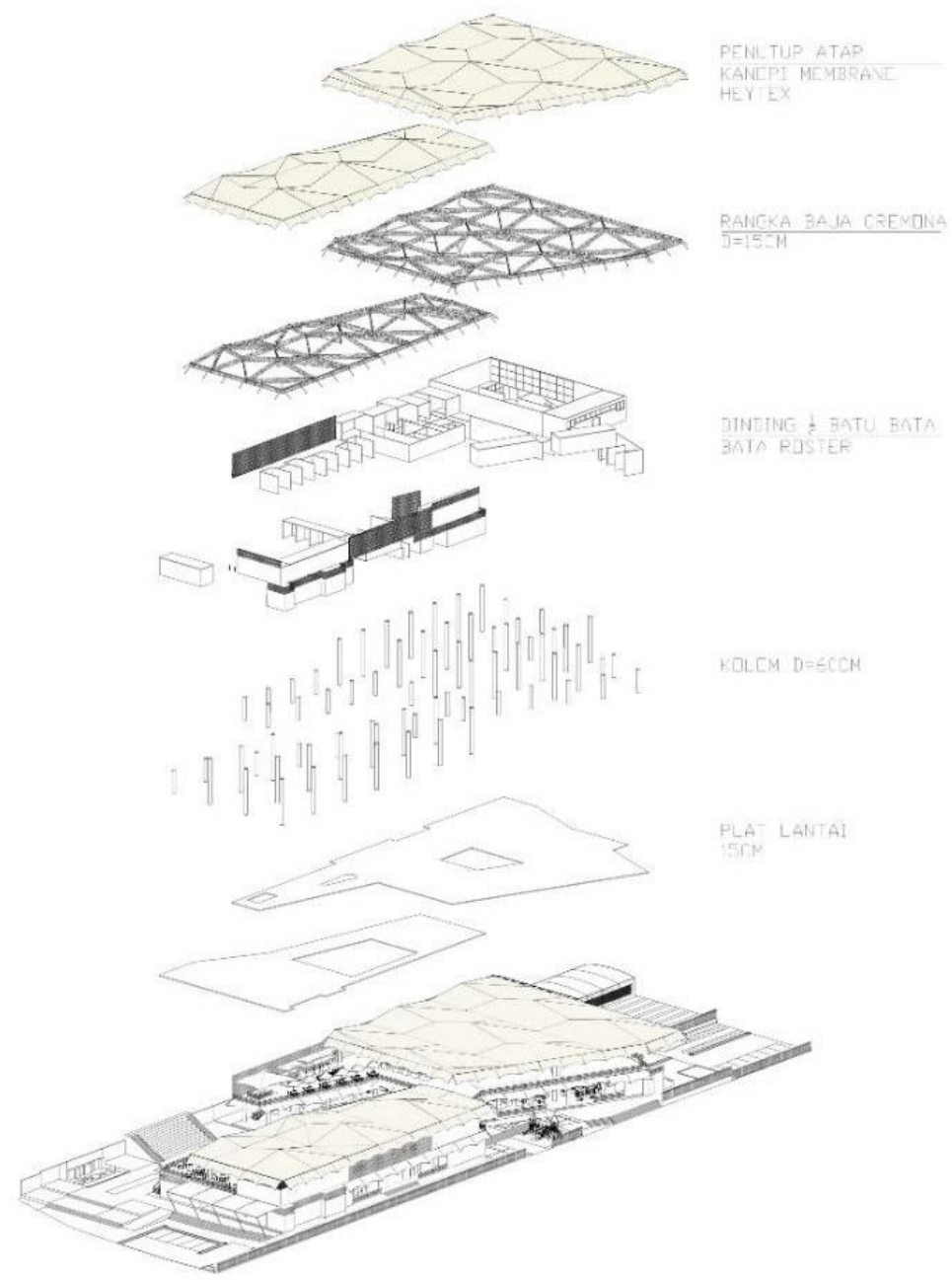

Gambar 7. Exploded Struktur

Sumber: Penulis, 2020

Material yang digunakan merupakan material yang kontekstual dengan lingkungan sekitar, tidak memberikan kesan mewah (low profile), material ini digunakan pada fasad, gerobak, dinding.
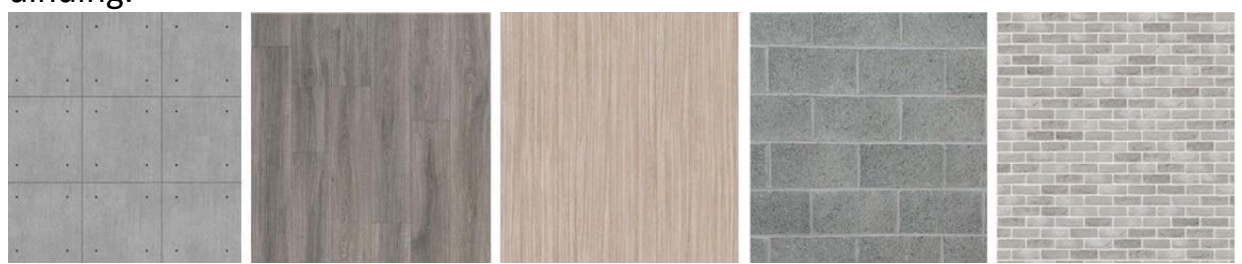

Gambar 8. Material pada bangunan Sumber: Penulis, 2020 

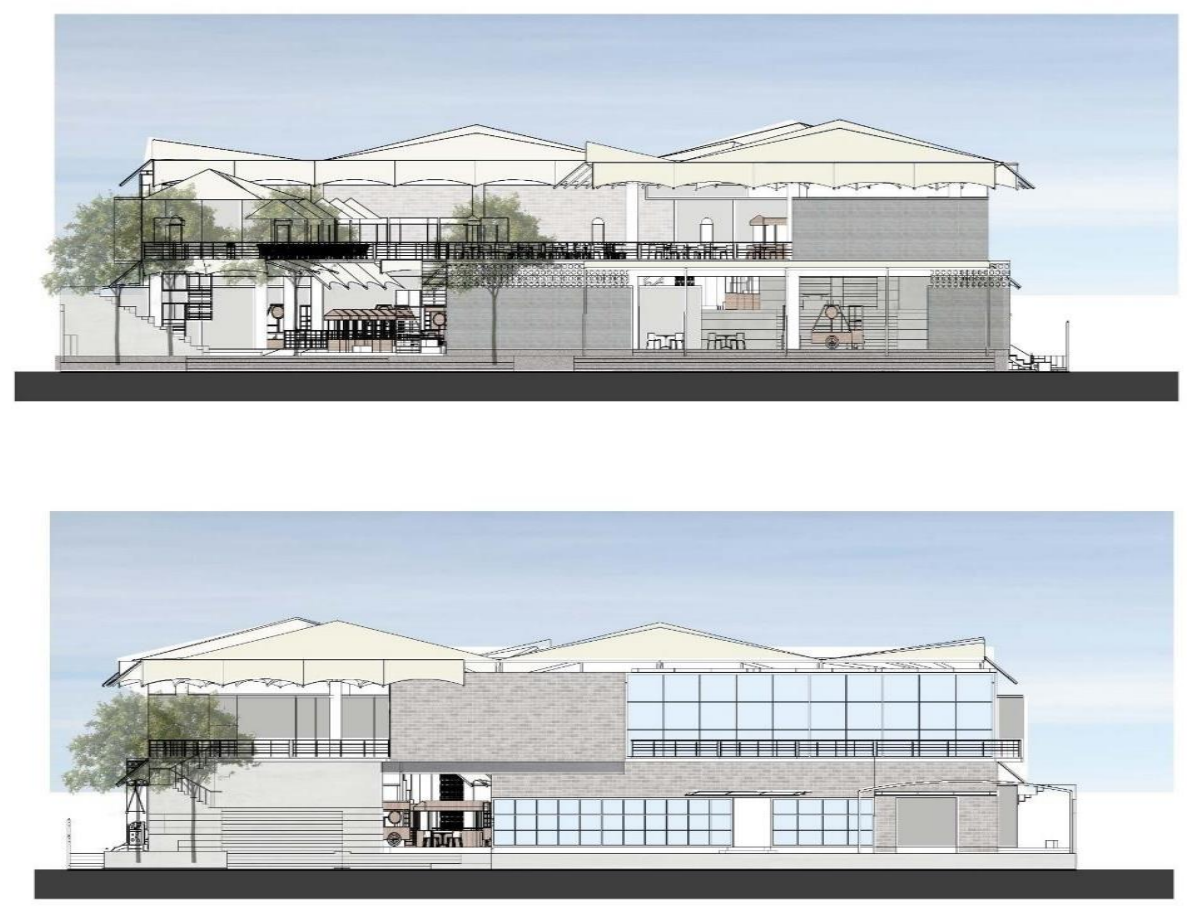

Gambar 9. Tampak depan dan belakang Sumber : Penulis, 2020

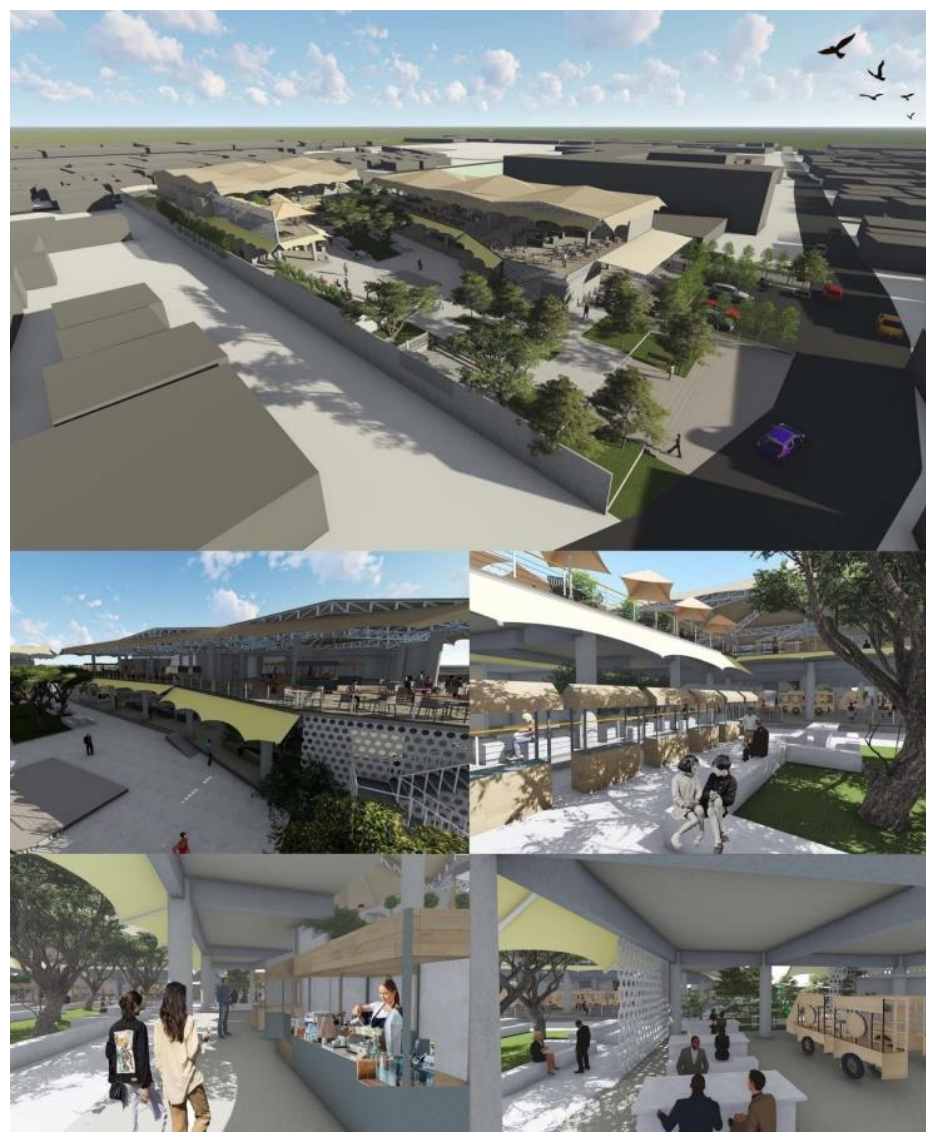

Gambar 10. Perspektif Eksterior dan Interior

Sumber: Penulis, 2020

Gambar diatas menunjukan perspektif eksterior dan interior di dalam bangunan, seperti area pedagang, area makan, area open space. 


\section{KESIMPULAN DAN SARAN}

\section{Kesimpulan}

Proyek ini berusaha untuk memberikan wadah bagi masyarakat Semanan yang Sebagian pekerjaan utamanya berdagang agar dapat memiliki tempat berdagang yang sesuai dengan kebutuhan. Selain itu, proyek ini berusaha untuk menjawab kebutuhan sekaligus menyelesaikan masalah yang ada di kawasan, seperti tidak terdapat area untuk bermain pada anak-anak, tidak adanya area terbuka hijau untuk masyarakat di kelurahan Semanan dan kurang nya minat masyarakat akan penghijauan lingkungan sehingga program-program tersebut diadakan yaitu berupa program Culinary \& Retail, Harvesting, Children Space dan Open/Public Space.

Dengan adanya Proyek ini, diharapkan pertumbuhan ekonomi dan pendapatan para pedagang kecil meningkat, masyarakat Semanan tertarik untuk bercocok tanam karena pentingnya unsur alam bagi kehidupan sehari-hari, anak-anak sekitar Semanan memiliki tempat bermain, dan terakhir masyarakat sekitar Semanan memiliki area terbuka hijau untuk bisa saling berinteraksi dan bersosialisasi satu dengan yang lain sekaligus melakukan aktivitas yang bermanfaat. Karena semua kegiatan merupakan bagian dari aktivitas manusia dalam berhuni.

\section{Saran}

Diharapkan, kedepannya, proyek ini dan proyek-proyek lainnya yang serupa dapat menjadi pembelajaran dalam memenuhi kebutuhan masyarakat setempat, terutama dalam hal peningkatan kualitas hidup.

\section{REFERENSI}

Broadbent, G. (1973). Design in Architecture. London: John Wiley \& Sons..

Heidegger, M. (1971). Building Dwelling Thinking. From Poetry, Language, Thought, translated by Albert Hofstadter. New York: Harper Colophon Books. http://home.lu.lv/ ruben/Building\%20Dwelling\%20Thinking.htm Jormakka, K. (2008). Basic Design Method. Basel: Birkhäuser

Norberg-Schulz, C. (1985). The Concept of Dwelling: on the way to figurative architecture. New York : Rizzoli

Sim, D. (2019). Soft City. Washington. Island press

Badan Pusat Statistik. (2018-2019). Diunduh 18 Agustus 2020, dari https://jakarta.bps.go.id/dynamictable/2019/11/11/69/3-1-1-penduduk-laju-pertumbuhanpenduduk-distribusi-persentase-penduduk-kepadatan-penduduk-rasio-jenis-kelamin-pendudukmenurut-kabupaten-kota-2018-2019.html 